general practitioners not to have become pregnant again within the year of follow up, although one attended for contraceptive advice.

Kaltreider $e t$ al reported on the feelings of doctors and nurses towards second trimester abortions done in theatre by dilatation and evacuation or in the ward using intra-amniotic methods and found that doctors and theatre nurses preferred the second method and ward nurses the first. ${ }^{6}$ In Tower Hamlets not all the ward staff or duty medical team felt able to take part in these late abortions, and this adds to the stress of those who do participate and may also be a factor in the consistently low proportion of very late abortions done in England and Wales.

Women requesting late abortions are, then, an atypical group with many social and psychological problems. A change in the law restricting legal abortion to 24 weeks' gestation or less would have prevented 78 abortions in 1982 and 87 in 1983, about a fifth of which were for fetal abnormality, ${ }^{7}$ and in Tower Hamlets would have prevented at least three deprived teenagers from ending their pregnancies and starting afresh. The close cooperation of a child psychiatrist has helped these vulnerable teenagers to cope.

My policy has been to assess each case on its merits and to try to minimise the psychological trauma to the mothers. I recognise that, regrettably, in some cases this has meant termination of pregnancy when the fetus was nearing natural viability.

I do not believe that the answer lies in a change in the law. Abortions at over 20 weeks are often associated with delay in the system as documented by many workers in this country ${ }^{8-10}$ and could be reduced in number by the provision of NHS day care facilities. Since the day care abortion service opened in July 1977 the proportion of abortions done at 17 weeks or more has fallen from $9 \%$ in 1975 to $1.8 \%$ in 1982 . In the small numbers of very late cases parents, teachers, and doctors are often in contact with the women concerned, and awareness of the possibility of pregnancy might enable an earlier diagnosis to be made.

I thank the Spencer Ward nurses, led by Sister Heyes, without whose humanity and unstinting support this work would not have been possible; my psychiatric colleagues Dr Alyson Hall and Dr Gillian Waldron for advice and after care; and Professor Colin Berry for providing pathology back up.

\section{References}

1 Paintin D. Late abortion 1984: problems and possibilities. In: Abortion services in London. London: Women's Reproductive Rights London Survey, 1984. (Report of a conference in 1984. Funded by the GLC Women's Committee.)

2 Alberman E, Dennis KJ, eds. Royal College of Obstericians and Gynaecologists late abortion survey. London: Royal College of Obstetricians and Gynaecologists, 1984: table 2.10.

3 Office of Population Censuses and Surveys. Abortion monitor AB83/5. London: OPCS, 1983.
4 Office of Population Censuses and Surveys. Abortion monitor AB84/6. London: OPCS, 1984.

4 Office of Population Censuses and Surveys. Abortion monitor AB84/6. London: OPCS, 1984. Ketting $\mathrm{E}$. Second trimester abortion as a social problem. In: Kierse
pregnancy termination. The Hague: Leiden University Press, 1982:16.

6 Kaltreider NB, Goldsmith S, Margolis AJ. The impact of midtrimester abortion techniques on patients and staff. Obstet Gynecol 1979;135:235-8.

7 Alberman E, Kani W, Stanwell-Smith R. Congenital abnormalities in legal abortions at 20 week or later. Lancet $1984 ;$; : $1226-7$.

8 Ashton JR. Components of delay amongst women obtaining termination of pregnancy. $\mathcal{J}$ Bioso Sci $1980 ; 12: 261-5$.

9 Allen I. Family planning and sterilization services. London: Policy Studies Institute, 1981.

10 Brewer $\mathrm{C}$. Induced abortion after feeling fetal movements. Its causes and emotional consequences. f Biosoc Sci 1978;10:203-8.

(Accepted 16 November 1984)

\title{
Measles matters, but do parents know?
}

\author{
S BLAIR, N SHAVE, J MCKAY
}

\begin{abstract}
Two hundred and one parents attending three child health clinics were questioned about both measles and immunisation against measles. Most parents were unaware of the symptoms and possible complications of measles and did not believe immunisation to be effective in preventing measles. They did not remember having talked to health professionals about immunisation.
\end{abstract}

\section{Introduction}

Britain has failed to immunise its population effectively against measles. ${ }^{1}$ Members of the Riverside Child Health Project were concerned about this and asked parents who were attending child health clinics for their views on measles and on immunisation against measles to see why many parents did not have their children immunised against measles.

\footnotetext{
Riverside Child Health Project, Atkinson Road Infant School, Newcastle upo Tyne

S BLAIR, MRCP, fellow and senior registrar in community paediatrics

University of Newcastle upon Tyne, Tyne and Wear

N SHAVE, medical student

J MCKAY, medical student

Correspondence to: Dr S Blair, Community Child Health Services, North Tyneside Health Authority, North Shields NE29 0HG.
}

The Riverside Child Health Project is based in an inner city area of Newcastle upon Tyne. The project team is responsible for developing community child health services in the area. Forty five per cent of children born in 1982 who attended the three child health clinics at Riverside were immunised against measles. ${ }^{2}$ The clinical experiences of the project's doctors in hospitals and the community had brought to their attention the suffering caused by measles and its more serious complications, particularly pneumonia and encephalitis.

\section{Subjects and methods}

A questionnaire was produced by the project team and used to ask parents their views about measles and its complications. They were also asked their views on the effectiveness of immunisation against measles and about any harmful effects or side effects and whether they had observed measles in their family or elsewhere. The parents' recollections of conversations with health professionals about measles were recorded. At the end of the interview parents were shown a flash card with a picture and description of three infectious diseases-namely, measles, chicken pox, and rubella. They were asked to identify which one they thought was measles.

The interviews were carried out by two medical students (JM, NS) over two and a half months. After each interview any issues raised by the interviewee were discussed with one of the two interviewers with reference to an information leaflet that the parents had received. ${ }^{3}$ The aim of this discussion was to improve parents' understanding of measles and measles immunisation and to overcome any misconceptions brought up in the interviews.

Two hundred and one parents, one for each child attending the clinics, were interviewed. Equal numbers of parents were seen at each clinic, and almost all of those asked agreed to participate: only six declined. The children attending the clinic at the time of this study were aged as follows: 0 3 months, 55 children; 4-6 months, 43; 7-11 months, 42 ; over 11 months, 61 . 


\section{Results}

We asked the parents whether they knew of anything serious that could happen, either during or after the illness, to a child with measles. Eighty eight said that they knew of serious events; of these, 40 named complications that were important and medically correct-that is, ear infection or deafness, bronchitis, pneumonia, fits, brain infection, and death ${ }^{4}$ Fifty nine parents mentioned eye complications-namely, blindness (20 parents), terms suggesting refractive errors (for example, a squint, will need glasses) (nine), and non-specific disorders (30). When shown the flash cards with illustrations of measles, rubella, and chicken pox 133 parents identified measles correctly.

Fifty three of the parents had had at least one child with measles; altogether 73 children had had measles. Of these, 23 were said to have suffered it in the first year of life.

Symptoms of measles described by parents were spots (179 parents) temperature (61), bad behaviour (37), sickness and diarrhoea (32), eyes affected (32), cold (19), and ears affected (five). Ninety three parents could not describe any symptoms or could describe only one, 59 described two and 49 described three or more. A higher proportion of parents who had had a child with measles than of those who had not had immediate experience of the disease named three or more symptoms $(p<0.002)$ and correctly identified measles from flashcards $\left(42 / 53\right.$ parents correct $v 91 / 145 ; \chi^{2}=$ $5.0563, \mathrm{p}<0.05)$.

The parents were asked whether they thought that measles immunisation stopped children catching measles always, usually, sometimes, or never. Twelve thought always, 58 usually, 99 sometimes, and 28 never; four did not know. Twenty three parents had heard of children being ill after measles immunisation. The illnesses they mentioned were a slight attack of measles (six); "off colour" (five); fever (four); sickness and diarrhoea (four); fits with temperature (one); and others (three). Thirty one parents thought that immunisation resulted in harmful effects. Twelve of them said that "everything has a risk," six said that it depended on the child's health, and five spoke of a a high temperature, three of brain damage, two of allergy, and three of other effects.

Sixty four parents said that they would not have their child immunised if he had measles before the immunisation was due; 112 would still have their child immunised; and 25 did not know and would ask for professional advice.

Ninety two parents said that they had talked to one or more of a health visitor, a doctor at a clinic, or a general practitioner about immunisation against measles. About half (105) did not remember talking to any professional. The proportions of parents with children of various ages who had spoken to professionals were 32 of the $55(58 \%)$ with children aged $0-3$ months; 13 of the $43(30 \%)$ with children aged $4-6$ months; 16 of the $42(38 \%)$ with children aged $7-11$ months; and 31 of the 61 (51\%) with children aged over 11 months. Previous discussion with a professional did not show any significant correlation with parents' views of measles or the effectiveness or side effects of immunisation.

\section{Discussion}

Analysis of parental views of measles and immunisation against measles shows that there are many areas of doubt and serious misconceptions about the disease. Many parents in our study thought that the only feature of measles was spots. Only $40(20 \%)$ of them named serious problems caused by measles that corresponded with the problems that health professionals were aiming to prevent by immunisation. Worse still, $127(63 \%)$ parents thought that immunisation was only sometimes or never effective. In fact, it is extremely effective and when used on a whole population can eradicate the disease. ${ }^{5}$

We were reassured to learn that most parents did not consider immunisation against measles to be harmful and were not concerned about its side effects. ${ }^{6}$ Thus these factors were not limiting the uptake of immunisation in our community. Our immunisation programme may have failed because parents were unaware of the nature of the illness and its potential complications. They did not appreciate the importance and effectiveness of immunisation against measles. Health professionals have an important part to play here. Half of our parents (105) did not remember having talked to a health professional about immunisation, and many had learnt about the illness only by seeing it within their own families. More effective communication with parents at an appropriate time in their child's life is needed. Local initiatives are vital, and we intend to produce an information leaflet discussing measles and immunisation against it based on the issues raised by this study. The leaflet will be used to augment professional advice. It will be given to parents on individual contact and at parent discussion groups. Our aim is that all parents will remember having talked to a health professional about immunisation by the time their child is a year old.

All children should be immunised against measles by the age of 2 whether or not they have been diagnosed as having had measles earlier in life. ${ }^{7}$ Such a programme would not only be extremely cost effective but would also reduce the misery of measles. ${ }^{8}$

We thank the members of the Riverside Child Health Project, clinic staff, and all the parents who participated in this study for their help.

\section{References}

1 Campbell AGM. Measles immunisation: why have we failed? Arch Dis Child 1983;58:3-5 2 Turner S. Riverside Child Health Project Evaluation Report, 1983. Newcastle upon Tyne: University of Newcastle upon Tyne, 1983:118-21.

3 Newcastle Health Education Department. Childhood infections, Riverside Health Project, 1982. Newcastle upon Tyne: Newcastle District Health Education Department, 1982. (Information leaflet.)

4 Nelson WE, ed. Textbook of Paediatrics. 11th ed. Philadelphia: W B Saunders, 1979:857-62. Noah ND. Measles eradication policies. Br Med f 1982;284:997.

6 Miller CL Surveillance after measles vaccination in children. Practitioner 1982:226:535-7.

7 Adjaye N, Marshall WC. Measles serology in children with a history of measles in early life. Br Med 1983:286:1478.

8 Mortimer EA. Immunisation against infectious disease. Science 1978;200:904

Accepted 15 November 1984
Is it true that young women whose mothers were treated with diethylstilboestrol during pregnancy face an increased risk of malignant disease or lower fertility?

Between the late 1940s and 1971 diethylstilboestrol was used, particularly in the United States, to treat various pregnancy disorders, and it is estimated that over one million women were exposed to diethylstilboestrol in utero. ${ }^{1}$ Structural abnormalities of the cervix and upper vagina are common among these women, and in 1974 a project was set up by the National Cancer Institute in the United States to investigate the incidence of these abnormalities. Of subjects identified by review of prenatal records, $25 \%$ had structural abnormalities, and among those referred to the project the figure was $43 \%$ $49 \% .^{2}$ These women are at risk of clear cell adenocarcinoma of the vagina or cervix, and the incidence of this condition has been estimated at $0 \cdot 14$ to $1 \cdot 4$ per 1000 diethylstilboestrol exposed women, with the peak incidence at 19 years of age. ${ }^{3}$ There have been isolated reports of other malignancies in both men and women exposed to diethylstilboestrol in utero, but there is no evidence that other malignancies are more common. The question of whether squamous carcinoma of the cervix is more common is unproved, and the incidence of cervical intraepithelial neoplasia is controversial. ${ }^{4}$ There is a wide variety of benign structural changes: cervical and vaginal abnormalities are markers for abnormalities of the fundus, which are associated with poor pregnancy outcome ${ }^{5}$ in the form of first and second trimester miscarriages, ectopic pregnancy, and premature labour. ${ }^{1}$ It has been suggested that women who have been exposed to diethylstilboestrol may be infertile because of cervical stenosis, ovulatory dysfunction, or endometriosis, but it remains uncertain whether they do have an increased incidence of infertility. ' - JAMES OWEN DRIFE, senior lecturer in obstetrics and gynaecology, Leicester.

1 Stillman RJ, Miller LC. Diethylstilbestrol exposure in utero and endometriosis in infertile females. Fertil Steril 1984;41:369-72.

2 Jefferies JA, Robboy SJ, O'Brien PC, et al. Structural abnormalities of the cervix and vagina in women enrolled in the diethylstilbestrol adenosis (DESAD) Project. Am 7 Obstet Gynecol 1984; 148:59-66.

3 Herbst AL. Current status of the DES problem. Obstet Gynecol Surv 1979;34:844-50.

4 Fowler WC. DES and CIN. Obstet Gynecol 1982;60:669.

5 Kaufman RH, Noller K, Adam E, et al. Upper genital tract abnormalities and pregnancy outcome in diethylstilbestrol-exposed pregnancy. Am $\mathcal{f}$ Obstet Gynecol 1984;148:973-84. 